\title{
A day in the life of an adolescent female with cystic fibrosis and the role of the advanced practice nurse: $A$ case study
}

\author{
Sigrid Ladores , Leigh A. Bray \\ School of Nursing, The University of Alabama at Birmingham, Birmingham, United States
}

Received: May 29, 2016

Accepted: July 14, 2016

Online Published: September 26, 2016

DOI: $10.5430 /$ jnep.v7n2p79

URL: http://dx.doi.org/10.5430/jnep.v7n2p79

\begin{abstract}
Cystic fibrosis (CF) is no longer considered a disease of childhood as life expectancy is continuously increasing. It is still a chronic life-limiting disease that presents unique physiological and psychological challenges to the adolescent who has it. Adolescence is a period of turbulence for teens with CF who face the primary issues of pulmonary exacerbations, complex medication and nutritional regimens, altered growth and development, and transition to adult health care. A pseudo-case study of a young adolescent girl with $\mathrm{CF}$ is presented to provide insight into the daily struggles that adolescents with $\mathrm{CF}$ undertake. The roles of the advanced practice nurse (APN) as clinician, case manager, and educator are highlighted in the provision of age-appropriate care.
\end{abstract}

Key Words: Cystic fibrosis, Adolescent, Advanced practice nurse

\section{INTRODUCTION}

Cystic fibrosis (CF) is a multi-system disease that affects over 70,000 people worldwide. ${ }^{[1]}$ It is transmitted as an autosomal recessive trait, with approximately one out of 31 Americans (or 10 million people worldwide) carrying the defective gene, making $\mathrm{CF}$ the number one genetic disorder among populations of European descent. ${ }^{[1]}$ It is caused by a mutation on chromosome 7, which produces the protein, cystic fibrosis transmembrane conductance regulator (CFTR). ${ }^{[1]}$ This protein regulates the movement of sodium and water across cell membranes, resulting in a disturbance of the exocrine gland's production of excessively thick, tenacious mucus. ${ }^{[2]}$ This leads to a variety of morbidities that affect the pulmonary, gastrointestinal and reproductive systems, among others.

According to the Cystic Fibrosis Foundation's patient reg- istry of 2012, approximately half of the 30,000 Americans with $\mathrm{CF}$ are age 18 and older. ${ }^{[1]}$ When $\mathrm{CF}$ was first described in the 1930's, most of these children died in infancy. ${ }^{[3]}$ With earlier detection and aggressive management of disease, $\mathrm{CF}$ is no longer considered a childhood disease, but a major chronic illness of adolescents and adults. With advances in research, drug discovery, and improved treatments, the median predicted survival age for people with CF has steadily climbed, rising from 31.3 to 41.1 years between the 2002 and 2012. ${ }^{[3]}$ With continually increasing life expectancy, it is imperative that adolescent developmental issues, in conjunction with the tasks of managing $\mathrm{CF}$, be explored and addressed for better patient outcomes. As a clinician, case manager, and educator, the advanced practice nurse (APN) specializing in cystic fibrosis care is in a unique position to

\footnotetext{
*Correspondence: Sigrid Ladores; Email: sladores@uab.edu; Address: School of Nursing, The University of Alabama at Birmingham, Birmingham, United States.
} 
teach and coordinate the complex care necessary to promote wellness in the adolescent with CF. The APN functions as a liaison between the patient, members of the health care team, family, school, and larger community. The APN facilitates open and timely communication among the aforementioned key players, and provides sensitive, age-appropriate care to the adolescent who strives to achieve crucial developmental milestones. A fictional case study of an adolescent female with cystic fibrosis is presented below to provide greater insight into the daily activities and struggles of this vulnerable group. The top health concerns for this vulnerable group will be highlighted, and the role of the APN will be delineated.

\section{Case presentation}

Mary is a fourteen-year-old Caucasian female with CF. She was diagnosed with $\mathrm{CF}$ at 2 months of age, after newborn screening and genetic testing results confirmed a homozygous F508del mutation. She has mild to moderate disease severity with forced expiratory volume in 1 second (FEV1) at $90 \%$ predicted. She has pancreatic insufficiency but does not have CF-related diabetes mellitus. She was hospitalized 4 times in the last 10 years for pulmonary infections with Pseudomonas aeruginosa. She is negative for Methicillin Resistant Staphylococcus aureus and Burkholderia cepacia. She lives with her parents and older brother; no one else in the family has CF. She is in eighth grade, maintains a full day of activities that includes her medical regimen, and has missed approximately 5 school days this year due to CF.

Her daily routine on school days includes waking up at six in the morning to prepare for the day ahead. She first takes her nebulized medications, which include a bronchodilator and a mucolytic agent, followed by her donning the "vest", an electronically-driven percussion device that promotes vibration within the chest walls, stimulating movement and dislodgement of the thick mucus from the lungs, making expectoration easier. The vest takes approximately 45 minutes to adequately percuss every lung segment. This is usually interrupted by coughing episodes, which may be prolonged and arduous. The morning continues with eating breakfast and taking multiple medications that include a prophylactic antibiotic, non-steroidal anti-inflammatory drug (NSAID), anti-ulcer and antacid agent, antihistamine agent, oral contraceptive agent, pancreatic enzymes, and vitamins. Before leaving for school, she takes another bronchodilator via an inhaler and an intranasal corticosteroid.

At school she has classes from nine in the morning until four in the afternoon, with a thirty-minute break for lunch, during which she has to take more medications including NSAID and pancreatic enzymes. She takes the inhaler with her to school in case of bronchospasmic episodes. Upon arriving home from school, her respiratory therapist delivers manual chest physiotherapy (CPT) with postural drainage. The therapy takes forty-five minutes to one hour with several coughing episodes throughout. She then relaxes, watches television, and talks with her family and friends. She completes homework and assignments before dinner, during which she takes more medications including NSAID, antibiotic, and pancreatic enzymes. Before bedtime she takes another nebulized bronchodilator and a stool softener. Then she dons on the therapy vest for another forty-five minutes of percussion while watching television before she retires to bed at $11 \mathrm{pm}$.

On the weekends her schedule varies somewhat. The respiratory therapist does not do home visits, thus, Mary uses the vest three times per day. She also engages in developmentally-appropriate activities such as "hanging out" with friends and her boyfriend. $\mathrm{He}$ is a classmate who is aware of her chronic illness but is "not bothered by it". Her friends, she reports, are "protective" of her and remind her to take her medications and eat "a lot". She has a handful of close friends who knows about her having CF, yet acquaintances and other classmates do not know. She works closely with her teachers who understand her need to leave the classroom at different times to go to the bathroom or to see the school nurse.

When asked about what is most troublesome to her, she reports that it is the relentless coughing and shortness of breath, especially upon waking in the morning. Her first class of the day is the toughest to get through because her lungs are "just waking up". She does not attempt to suppress her cough, yet is aware that people look at her "funny" when she cannot seem to stop coughing. Although CPT takes a significant portion of the day, she does not particularly find it troublesome because for most of the session she is asleep or watching television. However, when she is acutely ill, and coughing is harsh and frequent, CPT becomes a struggle.

The next most troublesome aspect in her medical regimen is taking a multitude of oral and inhalation medications. She tries to be consistent with taking her pancreatic enzymes with meals and snacks but may not remember especially at school. She recalls a time in 4th grade when she told inquiring classmates that the enzymes were "just vitamins".

Mary is between the 25-50th percentile for height and weight, yet is aware that most children with $\mathrm{CF}$ are thinner and shorter than her. She does not have the common pubertal delay that adolescent girls with CF experience. She had menarche at age 12. Her menstrual cycle was irregular until she was placed on the oral contraceptive, which promoted more regularity and less abdominal discomfort. Her pediatric $\mathrm{CF}$ care team has recently begun discussing her transition 
to adult health care, which "terrifies" both Mary and her parents because they have developed a long-term, trusting relationship with their pediatric team and are worried about establishing a similar relationship with the adult team.

\section{TOP HEALTH CONCERNS}

Adolescence is characterized by rapid changes in physiological, psychosocial and cognitive developments. ${ }^{[4]}$ It is a time when more complex emotional relationships and social interactions develop, along with a greater reliance on the peer group, a less dependent relationship with parents, and increasing legal autonomy. ${ }^{[5]}$ It is a turbulent time for healthy adolescents without chronic conditions, and can be especially turbulent for those with CF. It is a time when the adolescent with $\mathrm{CF}$ encounters more difficulties in incorporating the chronic illness into daily life, while trying to become independent and needing to feel in control of their disease. ${ }^{[6,7]}$ It is a time when compliance can become a problem and when the whole family needs extra support. ${ }^{[8]}$ As with many chronic illnesses, the severity of CF progresses from mild to moderate to severe as time passes. ${ }^{[9]}$ The physical manifestations and functional limitations of CF become more noticeable during adolescence. ${ }^{[8]}$ Therefore, it is a critical period when health issues can become magnified. A comprehensive list of health concerns is beyond the scope of this paper; however, the top four concerns are highlighted below.

\subsection{Pulmonary infections}

Females with CF have poorer respiratory function and survival than males from adolescence and onwards. ${ }^{[5]}$ To combat the recurrent pulmonary infections common in $\mathrm{CF}$, multiple inhalation and oral antibiotics are taken prophylactically, as well as other nebulized bronchodilators, mucolytics and/or corticosteroids. As exemplified by Mary's daily routine, there is a sequence to promoting optimum lung function. First, a bronchodilator is nebulized, followed by a mucolytic, then manual CPT and/or vest with postural drainage, and conclude with nebulized antibiotics if prescribed for current infections. This regimen is time consuming, physically exhausting, and interferes with other activities, especially at a time when the adolescent is striving for autonomy. The frequent cough and shortness of breath may be embarrassing to the adolescent, the former being cited as most troublesome to Mary. It is also a major indicator of worsening lung disease. ${ }^{[5]}$ People who have CF miss approximately 24 school or work days within a one year period due to lung infections. ${ }^{[10]}$ Furthermore, over recent years, treatments to prevent and treat pulmonary exacerbations have increased. The use of antibiotics has increased from approximately $54 \%$ in 2001 to $71 \%$ in $2007 .{ }^{[11]}$ The average cost of managing CF was approximately $\$ 48,000$ as of 2006 , which was over
$100 \%$ increase from 1996. ${ }^{[1]}$

\subsection{Nutrition}

Two common nutrition-related issues found in adolescents with $\mathrm{CF}$ are malnutrition and CF-related diabetes. Malnutrition is prevalent in the $\mathrm{CF}$ population due to the chronicity of illness, increased resting energy expenditure, and malabsorption of nutrients. ${ }^{[12]}$ It is a significant cause of complications and a major factor affecting survival in $\mathrm{CF} .{ }^{[7]}$ During the adolescent period, the caloric demands for growth and development accelerate. The adolescent with $\mathrm{CF}$, however, requires even more daily calories, approximately 120\%-150\% of the Recommended Daily Allowance (RDA), when there is pancreatic insufficiency that results in malabsorption. ${ }^{[13]}$ This malabsorption leads to steatorrhea, which can be embarrassing for the already self-conscious adolescent. Oral pancreatic enzyme supplementation is necessary to promote optimal absorption of nutrients, with a usual requirement of 1 to 10 capsules per meal to be taken. ${ }^{[14]}$ This may be difficult for the adolescent, especially in the school setting, because taking a handful of pills during lunch can make the adolescent appear "different" or "sickly". This could result in the adolescent avoiding meals, or eat without taking pancreatic enzymes; ${ }^{[15]}$ both behaviors can lead to malabsorption, abdominal pain, or even intestinal obstruction. ${ }^{[16]}$ Some adolescents prefer to lie about the pancreatic enzymes, as reported by Mary, stating that the capsules were "vitamins".

CF-related diabetes (CFRD) is the most common CF comorbidity. ${ }^{[16]}$ CFRD affects approximately $50 \%$ of adults and $20 \%$ of adolescents with CF. ${ }^{[17,18]}$ CFRD usually follows the worsening of CF symptoms and occurs in late adolescence. The additional treatment regimen can bring on more treatment burden and can lead to decreased treatment compliance. ${ }^{[19]}$ In fact, the onset of CFRD is associated with increased mortality. ${ }^{[5]}$ Additionally, CFRD further impacts lung health due to being associated with a lower lung function and higher airway glucose concentration. ${ }^{[18]}$

\subsection{Growth and development}

Growth delay is a common complication of $\mathrm{CF}$ that affects both males and females. It is during adolescence that the full impact of CF on reproductive health becomes clear. ${ }^{[4]}$ Pubertal development is found to be more delayed in females, which can negatively impact the adolescent's self-esteem. ${ }^{[4]}$ Menarche for adolescents with CF is delayed by approximately 2 years, with weight being a critical predictor. ${ }^{[4]}$ Interestingly, these adolescents with CF who are typically thin are not necessarily protected by society's current beauty standards that equates being beautiful with being thin. This further affects their development of self-concept and iden- 
tity. In fact, female adolescents with CF have significantly more self-esteem disturbance when compared to their male counterparts. ${ }^{[5]}$

\subsection{Transition to adult health care}

The transition from pediatric to adult heath care is a complex process that requires careful planning and execution. ${ }^{[6]}$ It is defined as a "potentially stressful and emotional process in which flexibility, and negotiation between the patient, parents, pediatric health care providers and adult health care providers are necessary in order to facilitate achievement of autonomous health-related decision-making and self-care within the adult health care setting". [6] The transition period is a time of vulnerability for adolescents with CF because of the impending change in care providers while they face the challenge of taking responsibility for their own health care decisions. ${ }^{[4,5]}$ Navigating the complex health care system can be overwhelming to the adolescent, and can lead to non-adherence in their medical regimens. ${ }^{[4]}$ Non-adherence stems from the combination of less parental supervision and the adolescents' desire to please their peers and be "just like everyone else". [4] While the American Academy of Pediatrics recommends that transition discussions begin at age 12 for those with chronic conditions, the dialogue does not often start in the CF population until age 17 , and only approximately $25 \%$ of CF centers offer visits focused on transition. ${ }^{[5]}$

\section{ROLE OF THE ADVANCED PRACTICE NURSE}

With early detection and aggressive management, the number of adolescents with CF living into adulthood is growing. During adolescence, the course of $\mathrm{CF}$ is characterized by an increasing severity of pulmonary disease that restricts an individual's functional ability to participate in activities with peers. ${ }^{[4]}$ This increasing severity in pulmonary disease can lead to frequent and lengthy hospitalizations and subsequent school absences. This can subsequently interrupt their ability to establish successful peer relationships. ${ }^{\text {[] }}$

Children with CF have some of the highest school-absence rates compared to children with other chronic illness due to the frequent clinic visits and hospitalizations. ${ }^{[7]}$ The APN specializing in $\mathrm{CF}$ care serves several vital roles to help promote a normal life for these adolescents and avoid hospitalizations as much as possible. As a clinician, the APN works collaboratively with the CF care team comprised of the pulmonologist, other medical specialists (e.g., gastroenterologist, endocrinologist, etc.), nurse, respiratory therapist, social worker, nutritionist, and lab technician, among others. The APN clinician develops treatment plans, monitors lab and radiologic results, adjusts and recommends medication regimens, and functions in both the hospital and clinic settings.

As a case manager, the APN is a critical member of the health care team in promoting continuity of care across various settings. First, the APN functions as a liaison between the adolescent, family, multidisciplinary health care team, educational system (e.g., teacher and school nurse), insurance companies, social services, and inpatient hospital staff. The APN is the common thread amongst the different key players and takes on the role of patient advocate. By establishing rapport with the patient and family, the APN can gather a more in-depth needs assessment and relay the information to the appropriate care team members to ensure the unique needs of each patient are met. Second, the APN coordinates the care of the adolescent with $\mathrm{CF}$, incorporating a holistic approach in providing age-appropriate care by engaging the adolescent in decisions and forming a partnership. ${ }^{\text {[] }}$ Third, the APN tackles the top concerns related to pulmonary toilet and medication regimen, nutrition, growth and development, and transition to adult health care as outlined above, while nurturing their need for independence in decision-making.

As an educator, the APN is an important source of knowledge, and disseminates current information about CF care. The APN is a teacher for the patient, parents, extended family members, and other health care team members. The teaching role is exhibited in each interaction with the adolescent with CF. An open communication, while avoiding an authoritarian approach, initiated by the CF care team will allay fears and concerns felt by these adolescent girls about their future relationships, and the possibility of reaching certain milestones that come with adulthood. ${ }^{[7]}$ For example, adolescents with mild CF disease may be reassured of their eventual sexual maturation; however, their fertility may be impaired due to abnormally thick cervical mucus, which acts as a barrier for sperm transport. ${ }^{[4]}$ Sexual and reproductive health must be discussed with these adolescent girls to avoid misconceptions and misinformation. An open dialogue about their emerging sexuality and natural desire for intimacy should be sensitively discussed and not neglected. These adolescent girls must understand the risks involved with unplanned pregnancy and consider the long-term implications of possible genotypic transmission to their offspring. ${ }^{[21]}$

It is especially important to monitor individual ideas of the illness course during the adolescent period when better understanding of the importance of adherence emerges, while discovering more about the progressive and irreversible trajectory of the disease. ${ }^{[7]}$ Ongoing assessment of the demands of CF and subsequent coping will allow the APN to recognize 
social concerns interfering with treatment goals and identify those at high risk for difficulties. ${ }^{[7]}$ Personalized teaching and peer networking with fellow adolescents with CF may be beneficial in providing anticipatory guidance and support for this vulnerable group. Fundamental to the role of the APN is the ability to listen to their life histories as children growing up with chronic illnesses, and attempt to understand and gain knowledge to better design interventions that will ultimately help them successfully live with the disease.

\section{Conclusion}

The adolescent female with cystic fibrosis presents with complex physical, emotional, and psychosocial needs. With advances in science, medicine, and technology, these adolescents are living longer and fuller lives. The advanced practice nurse is well positioned as a clinician, case manager, and educator, to positively impact these adolescents' chance to reach adulthood and engage in all developmental milestones.

\section{REFERENCES}

[1] Cystic Fibrosis Foundation (CFF). About cystic fibrosis [Internet]. 2016. Available from: http://www.cff.org/aboutcf/

[2] Cutting GR. Cystic fibrosis genetics: from molecular understanding to clinical application. Nat Rev Genet. 2014; 16(1): 45-56. PMid: 25404111 http://dx.doi.org/10.1038/nrg3849

[3] Cystic Fibrosis Foundation (CFF). Cystic fibrosis foundation patient registry: 2012 annual data report. [Internet]. 2013. Available from: http://www.cysticfibrosisdata.org/Literat ureRetrieve. aspx?ID=149756

[4] Withers AL. Management Issues for Adolescents with Cystic Fibrosis. Pulmonary Medicine. 2012; 1-10. PMid:22991662 http: //dx.doi.org/10.1155/2012/134132

[5] Ernst MM, Johnson MC, Stark LJ. Developmental and Psychosocial Issues in Cystic Fibrosis. Child Adolesc Psychiatr Clin N Am. 2010; 19(2): 263-83. PMid: 20478499 http://dx.doi.org/10.1016 /j.chc. 2010.01 .004

[6] Ladores S. Concept Analysis of Health Care Transition in Adolescents with Chronic Conditions. Journal of Pediatric Nursing. 2015; 30(5): e119-29. PMid:26195301 http://dx.doi.org/10.1016 /j.pedn.2015.06.003

[7] Segal TY. Adolescence: what the cystic fibrosis team needs to know. JRSM. 2008; 101(Supplement 1): 15-27. PMid:18607014 http://dx.doi.org/10.1258/jrsm.2008.s18005

[8] Bregnballe VSL. Parenting adolescents with cystic fibrosis: the adolescents' and young adults' perspectives. Patient Preference and Adherence. 2011; 563-70. PMid:22114471 http://dx . doi .org/10. 2147 /PPA.S25870

[9] Abbott J, Holt A, Hart A, et al. What defines a pulmonary exacerbation? The perceptions of adults with cystic fibrosis. Journal of Cystic Fibrosis. 2009; 8(5): 356-9. PMid:19665437 http: //dx.doi.org/10.1016/j.jcf.2009.07.003

[10] Elkins M, Robinson M, Rose B, et al. A controlled trial of long-term inhaled hypertonic saline in patients with cystic fibrosis. A controlled trial of long-term inhaled hypertonic saline in patients with cystic fibrosis. N Engl J Med. 2006; 354(3): 229-40. PMid: 16421364 http: //www.nejm.org/doi/pdf/10.1056/ne jmoa043900

[11] Briesacher BA, Quittner AL, Fouayzi H, et al. Nationwide trends in the medical care costs of privately insured patients with cystic fibrosis (CF), 2001-2007. Pediatric Pulmonology. 2011; 46(8): 770-6. PMid:21465674 http://dx.doi.org/10.1002/ppul. 21441
[12] Stephenson AL, Mannik LA, Walsh S, et al. Longitudinal trends in nutritional status and the relation between lung function and BMI in cystic fibrosis: a population-based cohort study. Am J Clin Nutr. 2013; 97(4): 872-7. PMid:23388659 http://ajcn.nutrition.o rg/content/97/4/872.full.pdfhtml

[13] Forte GC, Pereira JS, Drehmer M, et al. Anthropometric and dietary intake indicators as predictors of pulmonary function in cystic fibrosis patients. J Bras Pneumol. 2012; 38(4): 470-6. PMid:22964931 http://dx.doi.org/10.1590/S1806-37132012000400009

[14] Mössner J, Keim V. Pancreatic Enzyme Therapy. Dtsch Arztebl Int. 2011; 108(34-35): 578-82. PMid:21904592

[15] Oliver KN, Free ML, Bok C, et al. Stigma and optimism in adolescents and young adults with cystic fibrosis. Journal of Cystic Fibrosis. 2014; 13(6): 737-44. PMid:24795287 http://dx.doi.org/10. $1016 / j \cdot j c f .2014 .04 .005$

[16] Schindler T, Michel S, Wilson AWM. Nutrition Management of Cystic Fibrosis in the 21st Century. Nutr Clin Pract. 2015; 30(4): 488-500. PMid:26113561 http://dx.doi.org/10.1177/08845 33615591604

[17] Moran A, Brunzell C, Cohen RC, et al. Clinical Care Guidelines for Cystic Fibrosis-Related Diabetes: A position statement of the American Diabetes Association and a clinical practice guideline of the Cystic Fibrosis Foundation, endorsed by the Pediatric Endocrine Society. Diabetes Care. 2010; 33(12): 2697-708. PMid: 21115772 http://dx.doi.org/10.2337/dc10-1768

[18] Stecenko AA, Moran A. Update on cystic fibrosis-related diabetes. Curr Opin Pulm Med. 2010; 16(6): 611-15. PMid:20814309 http: //dx.doi.org/10.1097/MCP.0b013e32833e8700

[19] Perano S, Rayner C, Couper J, et al. Cystic fibrosis related diabetes-a new perspective on the optimal management of postprandial glycemia. Journal of Diabetes and its Complications. 2014; 28(6): 904-11. PMid:25060530 http://dx.doi.org/10.1016/j.jdi acomp. 2014.06.012

[20] American Academy of Pediatrics. Supporting the Health Care Transition from Adolescence to Adulthood in the Medical Home. Pediatrics. 2011; 128(1): 182-200. PMid:21708806

[21] Tsang A, Moriarty C, Towns S. Contraception, Communication and Counseling for Sexuality and Reproductive Health in Adolescents and Young Adults with CF. Paediatric Respiratory Reviews. 2010; 11(2): 84-9. PMid:20416543 http://dx.doi.org/10.1016/j.p rrv. 2010.01.002 